\title{
Growing Cyberceptive Organs within Electronic Environments
}

\author{
Živa Ljubec \\ Planetary Collegium \\ Plymouth University \\ Plymouth PL4 8AA, UK \\ Ziva.Ljubec@gmail.com
}

\begin{abstract}
1. ABSTRACT
While technology is overgrowing our primal environments, transferring our activities into intermediary electronic environments, how do we adapt our cognition to increasing complexity of Cyberia's (Rushkoff 1994) information landscapes? During the inevitable and persistent uploading of our minds into cyberspace how do we envision evolution of our cognitive organs inventing the technology that at the same time influences us through a feedback loop? If artists remain at the forefront by recognising the changes, deviations, traps and advantages of such feedback loops, should the mindset of our mutating cognitive organism be that of an artist? How are engineers participating in the creative act of an artist? These and other questions will be addressed in this research in order to consider both the design of the electronic environments we are submerging ourselves into and the fertility of such terrains to grow and augment our minds.
\end{abstract}

\section{APPROACH}

With immersion of the mind into an ambient of mathematically infinite potential, the mind is at liberty to evolve and expand its cognitive organs in any direction. If the ambient does not impose constraints, and if the mind is not limited with predetermined sensory organs, the mind is able to wander freely in a flux of change, mutating its organisation with every encountered challenge. By escaping the dominance of the visual sense, this research examines the possibilities to grow the cognitive organs out of other senses, such as the sense of touching and grasping the datascape through imaginary virtual organism of the real mind in order to simulate a direct experience (Kerckhove 1990) - an immediate knowing of the body in touch with the raw data.
Already the artists of pre - computerised era, such as František Kupka, inspired by the physics of electromagnetic waves, wondered about a more direct engagement with their spectators, an engagement that bypasses the need for representation and externalisation of the artist's experience that is to be shared. With computerisation, this tendency towards such immediate collective experience reaches beyond the computer screens or head mounted displays, data gloves and other externally wearable prostheses into speculations on neural rewiring of our organisms into neurocinemas (Weibel 2003), augmented for direct cyberception (Ascott 2003).

While Weibel (2003, p. 599) introduces a possibility of immediate "perception without the senses" and "seeing without the eyes," where neural "stimulation ... would replace simulation," Ascott (2003, pp. 320, 321) announces how such "telematically shared" capability of "cyberception heightens transpersonal experience." Not only are the boundaries of our individuality and identity dissolved and destabilised, and we gain the "capacity to be out of body or in mind - to - mind with others," furthermore, cyberception is not limited to one mode of perception of a singular reality but can adapt to any virtual reality.

In accordance with McLuhan's (1994, p.18) notion of a "serious artists" as "the only person able to encounter technology with impunity, just because he is an expert aware of the changes in sense perception," this research therefore anticipates our technologically accelerated evolution into cyberceptual organisms through the uncompromised foresight of the arts. Just as the animal evolves into an amphibian to survive and thrive in both terrestrial and aquatic environments, the artist evolves into a polyphibian, adapting her organs of perception to multiple technological variations of cybernetic environments. 
The artist is the crucial ingredient in technological development since she is immune to narcotic effect that technology induces in its users, including the engineers themselves. By recognising the changes in rates of perception the artist survives with acute alertness the process of autoamputation of the old perceptive organs and thrives through mutations into ever new cyberceptive organism. McLuhan (1994, p.42) explains our body's strategy to autoamputate "when the perceptual power cannot locate or avoid the cause of irritation," pointing to the "desperate and suicidal autoamputation," where our entire central nervous system is replaced by the electric circuitry as if it "could no longer depend on the physical organs." It is not only our physical organs that are being replaced by technology, our organisation of thinking processes must likewise adapt and/or autoamputate its obsolete thinking patterns under the increasing rate of technological stimulations.

If amphibians are capable of self - transformation in the switch - over between adjacent physical environments, the artists as polyphibians mutate their perceiving and processing organs in the simultaneous encounters with the multiplicity of cybernetic environments. With technologically induced mutations of our intellectual faculties several parallel evolutions are taking place, such as artificial intelligence (AI) and intelligence amplification (IA), where Frederick Brooks explains the difference: "In the Al community, the objective is to replace the human mind by the machine and its program and its data base. In the IA community, the objective is to build systems that amplify the human mind by providing it with computer - based auxiliaries that do the things that the mind has trouble doing." (Rheingold 1992, p.37).

The mind is troubled by its rigidity in confrontation with its boundaries. For the "intelligence amplification" to succeed, the engineer must awaken to her artistic, protoplasmic state of mind and mutate her intellectual organs into polyphibic organs of knowing. The answer to the question what could be the trigger for intellectual mutation is already well known to humans. The limitations of the human intellect are naturally dissolved through laughter - by laughing at our own constraints we open up to the otherness in us. The void of the unknown we gaze into at the precipice, after the unavoidable avalanche of laughter, is immediately swelled by imagination. Laughter and imagination work in cooperation. The polyphibic organs of knowing are therefore the imaginary organs that we invent out of the protoplasmic state of mind. It takes not only the serious artist, as McLuhan proposed, but the artist with serious humour to harness the available technology in order to share these imaginary inventions.
Frank Popper (2007, p.80) in contrast to the "arts of earlier eras" offers a list of "the five defining features of Ascott's art and indeed of the art of our time [...]: connectivity, whether part to part, person to person, or mind to mind; immersion into the whole, and thus the dissolution of subject and ground; interaction as the very form of art, such that art as behaviour of forms has become art as a form of behaviour, transformation via the perpetual flux of image, surface and identity; and emergence, the perpetual coming into being of meaning, matter and mind." Connectivity, immersion, interaction, transformation and emergence in the process of mutation of cyberceptive organs make the intermediary intellectual instruments and modes of representation obsolete. With advances in our technological environments the degrees of freedom of perception and conception augment, we are free to plug into a direct experience of the electronic collective nervous system where knowledge is to be lived instinctively and immediately rather than filtered through intellectual interfaces. The rate of advancement depends on dynamics of the protoplasmic state of Cyberia where polyphibians incessantly adapt to new ways of knowing through mutations of their cyberceptive organs.

\section{REFERENCES}

Ascott, R. (2003) The Architecture of Cyberception. In E. A. Shanken (ed.), Telematic Embrace. Visionary Theories of Art, Technology and Consciousness. University of California Press, Berkeley, California.

Kerckhove, D. de (1990) Virtual Reality for Collective Cognitive Processing. Digital Dreams Virtual Worlds. Ars Electronica Catalog Archive. http://90.146.8.18/en/archives/festival archive/festi val catalogs/festival artikel.asp?iProjectID $=8972$ (retrieved 7 January 2015)

McLuhan, M. (1994) Understanding Media: The Extensions of Man. The MIT Press, Cambridge, Massachusetts.

Popper, F. (2007) From Technological to Virtual Art. The MIT Press, Cambridge, Massachusetts.

Rushkoff, D. (2002) Cyberia: Life in the Trenches of Hyperspace. Clinamen Press, Manchester.

Rheingold, H. (1992) Virtual Reality: The Revolutionary Technology of Computer Generated Artificial Worlds - and How It Promises to Transform Society. Touchstone, Simon \& Schuster, New York.

Weibel, P. (2003) The Intelligent Image: Neurocinema or Quantum Cinema? In S. Jeffrey \& W. Peter (eds), Future Cinema: The Cinematic Imaginary After Cinema. The MIT Press, Cambridge, Massachusetts. 